\title{
Diversity of Bacillus cereus sensu lato mobilome
}

Nancy Fayad ${ }^{1,2}$, Mireille Kallassy Awad ${ }^{2}$ and Jacques Mahillon ${ }^{1^{*}}$ (D)

\begin{abstract}
Background: Bacillus cereus sensu lato s.l.) is a group of bacteria displaying close phylogenetic relationships but a high ecological diversity. The three most studied species are Bacillus anthracis, Bacillus cereus sensu stricto and Bacillus thuringiensis. While some species are pathogenic to mammals or associated with food poisoning, Bacillus thuringiensis is a well-known entomopathogenic bacterium used as biopesticide worldwide. B. cereus s.l. also contains a large variety of mobile genetic elements (MGEs).

Results: In this study, we detail the occurrence and plasmid vs. chromosome distribution of several MGEs in 102 complete and annotated genomes of B. cereus s.I. These MGEs include 16 Insertion Sequence (IS) families, the Tn3 family, 18 different Bacillus cereus repeats (BCRs) and 30 known group II introns.
\end{abstract}

Conclusions: Our analysis not only shows the diversity of these MGEs among strains of the same species and between different species within the B. cereus s.l. group, but also highlights the potential impact of these elements on the plasticity of the plasmid pool, and the TEs (Transposable Elements) - species relationship within B. cereus s.l.

Keywords: Bacillus anthracis, Bacillus cereus repeats, Bacillus thuringiensis, Group II introns, Insertion sequences, Transposons

\section{Background}

Bacillus cereus group, also known as B. cereus sensu lato s.l.), is a group of Gram-positive spore-forming bacteria that comprises nine ecologically diverse species with a wide pathogenicity spectrum [1], despite being phylogenetically close. The most studied species of this group are $B$. anthracis, the anthrax causative pathogen $[2,3]$, B. cereus sensu stricto (s.s.), to which belong foodborne pathogenic strains, and B. thuringiensis, an entomopathogenic bacterium widely used as biopesticide $[4,5]$. $B$. thuringiensis insecticidal toxins, also known as $\delta$-endotoxins, form a parasporal crystal, released in the environment at the end of the sporulation phase. The six other species are Bacillus weihenstephanensis [6], Bacillus cytotoxicus [7], Bacillus mycoides, Bacillus pseudomycoides [8], Bacillus toyonensis [9] and Bacillus cereus biovar anthracis [10]. Recently, Bacillus gaemokensis [11], Bacillus manliponensis [12], Bacillus

\footnotetext{
* Correspondence: jacques.mahillon@uclouvain.be

${ }^{1}$ Laboratory of Food and Environmental Microbiology, Earth and Life Institute, UCLouvain, Croix du Sud, 2 - L7.05.12, B-1348 Louvain-la-Neuve, Belgium

Full list of author information is available at the end of the article
}

bingmayongensis [13] and Bacillus wiedmannii [14] have also been suggested as distinct species of this group.

Over the years, the phylogeny of B. cereus s.l. has been extensively analysed. In fact, classification of the species within this group is crucial given the intensive use of $B$. thuringiensis in the field. However, the species delineation between $B$. thuringiensis and $B$. cereus s.s. within the $B$. cereus group has been problematic despite the various approaches and techniques used. The efforts to distinguish between these two species have used phenotypical observations [15], 16S rRNA and housekeeping genes analysis [16] and whole-genome based approaches. The B. cereus s.l. pan-genome consists of about 60,000 genes, with 600 core-genes. Using this pan-genome and several phylogenetic approaches, followed by a Bayesian model, population genetic analysis revealed that $\mathrm{B}$. cereus s.l. is mainly divided into three clades [17]. Similarly to other studies though, either based on MLST (Multi Locus Sequence Typing), maximum-likelihood phylogeny or peptidome analysis, the $B$. thuringiensis and $B$. cereus distinction within the three clades could not be resolved [17-20]. Another study however was able to make the distinction between $B$. cereus s.s., $B$. 
thuringiensis and $B$. anthracis by combining a digital DNA-DNA hybridization technique, 16S rRNA and housekeeping gene analysis, a novel MLST approach and screening of toxin-coding genes [21]. This study divided 224 analysed $B$. cereus s.l. genomes into 30 groups, each representing independent species with 19 new ones. Yet another study was also able to differentiate B. cereus s.l. species on a plasmidial level using Genome Target Evaluator (GTEvaluator) and several genetic markers [22]. In fact it was suggested that plasmids, especially large toxin-carrying plasmids, play a crucial role in the phenotypical heterogeneity of the B. cereus group [23]. Not only do $B$. thuringiensis strains possess variable plasmid numbers, but also these plasmids are very versatile. They may carry the delta-endotoxin coding genes, such as pBtoxis in B. thuringiensis sv. (serovar) israelensis [24, 25], and some are conjugative (e.g. pXO16, [26] and pAW63, [27]), mobilizable or of prophage-like nature $[5,28]$.

Mobile Genetic Elements (MGEs) have likely played an important role in the genomic plasticity displayed by members of the B. cereus group. They consist of conjugative and mobilizable plasmids, such as pAW63 and pXO16 in B. thuringiensis [29, 30], Integrative and Conjugative Elements (ICEs) [31] and bacteriophages (phages). But they also include Transposable Elements (TEs) [32], such as Insertion Sequences (ISs, [33]), Class II transposons (Tns, [34]), Mobile Insertion Cassettes (MICs, [35]), Miniature Inverted repeat Transposable Elements (MITEs), Integrons [36], group II introns and $B$. cereus repeats (BCRs, [37]). ISs and Tn elements are often associated with virulence genes in B. cereus s.l. [38-40]. Each of these TEs presents a specific organization and transposition mechanism. ISs, MICs, Tns and MITEs all rely on the presence of an active transposase for mobility, whereas Integrons and ICEs use integrase and excisionase enzymes, as well as a recombination site.

ISs are prokaryotic transposable elements with a simple organization: two terminal inverted repeats (IR) flanking a transposase-coding gene, with certain exceptions such as those of the IS200/IS605 family that display sub-terminal palindromic structures [41]. ISs are ubiquitous among prokaryotic genomes, with a differentiated distribution between chromosomes and plasmids $[42,43]$. The complex class II transposable elements are represented in B. cereus s.l. by elements belonging to the Tn3 family [34]. These elements, also flanked by terminal inverted repeats, carry a transposase and resolvase genes and occasionally one or more passenger genes.

The first $B C R$ element was shown to exhibit mobile DNA features and to be restricted to the B. cereus s.l. group. Seventeen more elements were identified, characterized and divided into 3 groups: group A (bcr1 - bcr3),
B (bcr4 - bcr6) and C (bcr7 - bcr18) [44]. The mobility of these elements is associated with a possible site-specific recombination-like mechanism, associated with the presence of one or more repetitions of a "TTTAT" motif.

As for group II introns, they are ubiquitous among bacterial genomes. Group I and II introns, discovered more than 20 years ago, are self-splicing catalytic RNAs, widespread in all bacterial genomes, including those of B. cereus s.l. They are characterized by complex secondary RNA structures, which play a key role in their mobility $[45,46]$. The majority of group II introns encode IEPs (Intron Encoded Proteins), which insure their reverse transcription and aid in their movement within the genome $[47,48]$. Group II introns are divided into three main families of RNA secondary structures: IIA, IIB and IIC [47].

In the present study, 102 complete and annotated $B$. cereus s.l. genomes were analysed for the prevalence and diversity of their TEs. This included the nine B. cereus s.l. species that displayed at least one complete genome available in the database. The analysed MGE types were IS elements, class II transposable elements belonging to the Tn3 family, consensus $B C R$ sequences and group II introns. A particular interest was also set on elements present on B. thuringiensis toxin-carrying plasmids.

\section{Results}

\section{B. cereus sensu lato genomes}

One hundred and two complete genome sequences belonging to B. cereus s.l. were retrieved from the NCBI (National Center for Biotechnology Information) genome database (Table 1). Of the forty-two complete genomes assigned in the NCBI database as $B$. thuringiensis, eight strains did not contain any delta-endotoxins and were marked as "cry- "(crystal-). These strains included Bt407 and BMB171, two derivatives of wild-type crystalliferous strains, artificially cured by cultures at high temperatures $[49,50]$. The six other strains included the debated pathogenic B. thuringiensis sv. konkukian strain 97-27, which should have been referred to as B. cereus [29]. As for B. cereus s.s., four strains contained parts of cry or cyt (cytotoxin) coding genes. The accession numbers of the analysed genomes and the details of the B. thuringiensis cry- and B. cereus cry+ strains, grouped together as B. thuringiensis-like, are given in (Additional file 1: Table S1).

The most striking difference between species resides at the level of their plasmid content. This is particularly remarkable in the case of $B$. thuringiensis strains that harbour an average of 6.4 plasmids per strain and contain $11.2 \%$ of plasmidial DNA, as compared to the B. cereus s.s. strains with an average of two plasmids per strain, totalizing only $4.2 \%$ of plasmid DNA (Table 1 ). 
Table 1 Genomic details of the analyzed B. cereus s.I. species

\begin{tabular}{|c|c|c|c|c|c|c|}
\hline & $\begin{array}{l}\text { Number } \\
\text { of } \\
\text { genomes }\end{array}$ & $\begin{array}{l}\text { Average } \\
\text { chromosome size } \\
\text { per strain (bp) }\end{array}$ & $\begin{array}{l}\text { Average plasmid } \\
\text { number per } \\
\text { strain }\end{array}$ & $\begin{array}{l}\text { Minimum-Maximum } \\
\text { plasmid number per } \\
\text { strain }^{\text {a }}\end{array}$ & $\begin{array}{l}\text { Minimum-Maximum } \\
\text { plasmid length per strain } \\
\text { (bp) }{ }^{\mathrm{a}}\end{array}$ & $\begin{array}{l}\text { Plasmid } \\
\text { percentage of the } \\
\text { genome (\%) }\end{array}$ \\
\hline B. thuringiensis & 36 & $5,534,498$ & 6.4 & $1-14$ & $9261-761,374$ & 11.2 \\
\hline $\begin{array}{l}\text { B. cereus sensu } \\
\text { stricto }\end{array}$ & 42 & $5,312,889$ & 2 & $1-7$ & $2931-715,614$ & 4.21 \\
\hline B. thuringiensis-like & 8 & $5,417,908$ & 1.8 & $1-6$ & $14,888-591,112$ & 7.56 \\
\hline B. anthracis & 6 & $5,223,964$ & 1.8 & $1-2$ & $94,758-181,793$ & 4.75 \\
\hline B. mycoides & 4 & $5,327,723$ & 5.5 & $3-8$ & $4602-460,379$ & 9.49 \\
\hline $\begin{array}{l}\text { B. } \\
\text { weihenstephanensis }\end{array}$ & 2 & $5,435,562$ & 2.0 & $N R$ & NR & 5.31 \\
\hline B. pseudomycoides & 1 & NR & NR & $N R$ & NR & 0 \\
\hline B. cytotoxicus & 1 & NR & NR & NR & NR & 0.17 \\
\hline B. toyonensis & 1 & NR & $N R$ & NR & NR & 1.69 \\
\hline $\begin{array}{l}\text { B. cereus biovar } \\
\text { anthracis }\end{array}$ & 1 & $N R$ & NR & $N R$ & $N R$ & 5.30 \\
\hline
\end{tabular}

NR Not Relevant

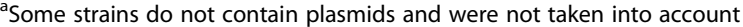

\section{IS and Tn3 elements}

As shown in Fig. 1 (a - d), sixteen ISs and Tn3 families are represented by at least one copy in B. cereus s.l. Four noteworthy observations can be made on these data. The first observation concerns the copy number of ISs and Tn3-related elements, which varies between the nine B. cereus s.l. species (Fig. 1). Our data showed that the number of IS copies of a family also varies among strains of the same species, where $B$. thuringiensis strains tend to have higher copy numbers for certain families. This is for instance the case for the IS3 family. The copy number of its elements varies between one and 63 copies per strain with an average of 14.3 elements in B. thuringiensis, vs. (versus) a variation between one and 17 and an average of 5.5 elements in B. cereus s.s. (Fig. 1a and b, respectively).

The second observation is about the distribution of ISs and Tn3-like elements among the different species of the $B$. cereus group. Families such as IS3, IS4 and IS200/ IS605 are ubiquitous among B. cereus s.l. while others, such as IS1, IS30 and IS982, are rarely present (Figs. 1 and 2). Some families, despite their high copy number, are present in only a few strains. This is illustrated by the IS 5 family that has a total of 158 copies in B. thuringiensis, but unevenly distributed among only four strains (Fig. 2). Therefore, this IS family cannot be considered as a potential marker for B. thuringiensis. However, as for the widely distributed IS families, their higher copy number in B. thuringiensis, as a whole, distinguishes this species from the other B. cereus group members (Fig. 2).

Thirdly, the distribution of these elements between the chromosomes and plasmids varies considerably according to the TE family. For instance, as shown in Fig. 3, IS607 family is strictly chromosomic, in contrast to IS6 family which is plasmid-borne at 100, 99 and $95 \%$ of the time for B. thuringiensis-like, B. thuringiensis and B. cereus s.s., respectively. Members of the IS4 family can be both chromosome- or plasmid-borne. As for Tn3 family members, they are mostly found on plasmids (Fig. 3).

Finally, the average size of each family, the total number of ISs and Tn3-like elements present in each species provided us with a total ISs and Tn3-like elements size, used to calculate the percentage of TEs vis-à-vis of the total analysed genome, chromosome or plasmid size. As a whole, $B$. thuringiensis possesses the highest percentage $(1.67 \%)$ of its genomes, which is related to ISs and Tn3-like elements, followed by B. mycoides (1.29\%) and B. cereus biovar anthracis (0.93\%). For B. thuringiensis, $B$. cereus s.s. and B. anthracis, the chromosomal vs. plasmidial IS/Tn3-like percentages varied greatly between the three species: while the chromosomal percentage is $1.10 \%$ in B. thuringiensis, $0.36 \%$ in B. cereus s.s. and $0.11 \%$ in $B$. anthracis, at the plasmidial level, B. anthracis has the highest percentage of $7.07 \%$, followed by $B$. thuringiensis $(6.18 \%)$ B. thuringiensis-like strains (4.50\%) and finally B. cereus (3.73\%).

\section{B. cereus repeats (BCRs)}

Eighteen $B C R$ repeated DNA elements, ranging from 100 to $400 \mathrm{bp}$, were also analysed in the complete genomes of B. cereus s.l. Their distribution among the 102 analysed B. cereus s.l. genomes is shown in (Additional file 1: Table S2). Bcr1 is the most abundant element with a maximum of 130 integral copies in B. mycoides strains Gnyt1, a minimum of 11 copies in B. anthracis strains, and an average of 39 repeats per B. cereus s.l. strain. As for groups $B$ and $C$, an average of two repeats per strain was found. Bcr1, bcr4, bcr6, bcr10, bcr13 and bcr16 have 

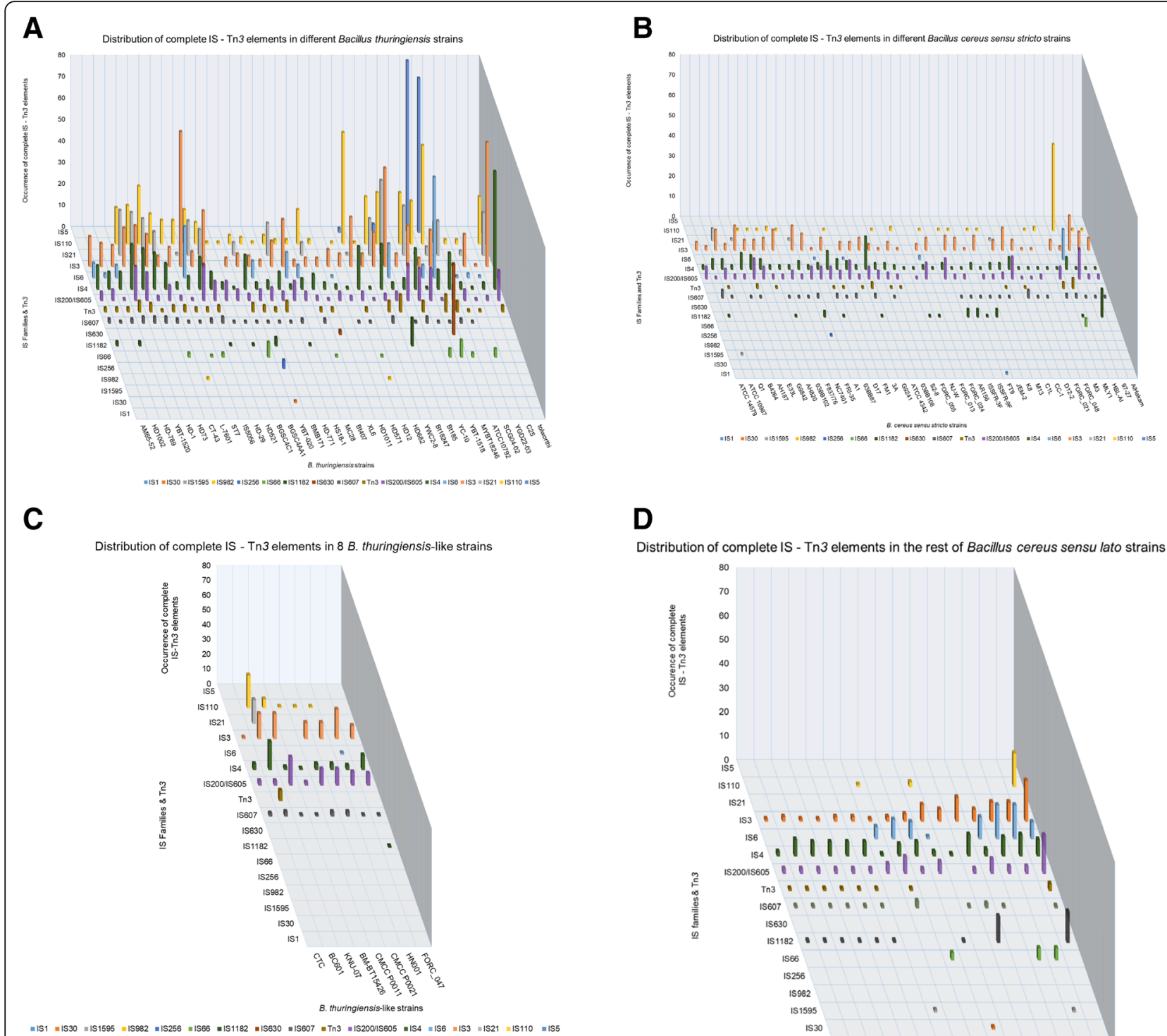

\section{D}

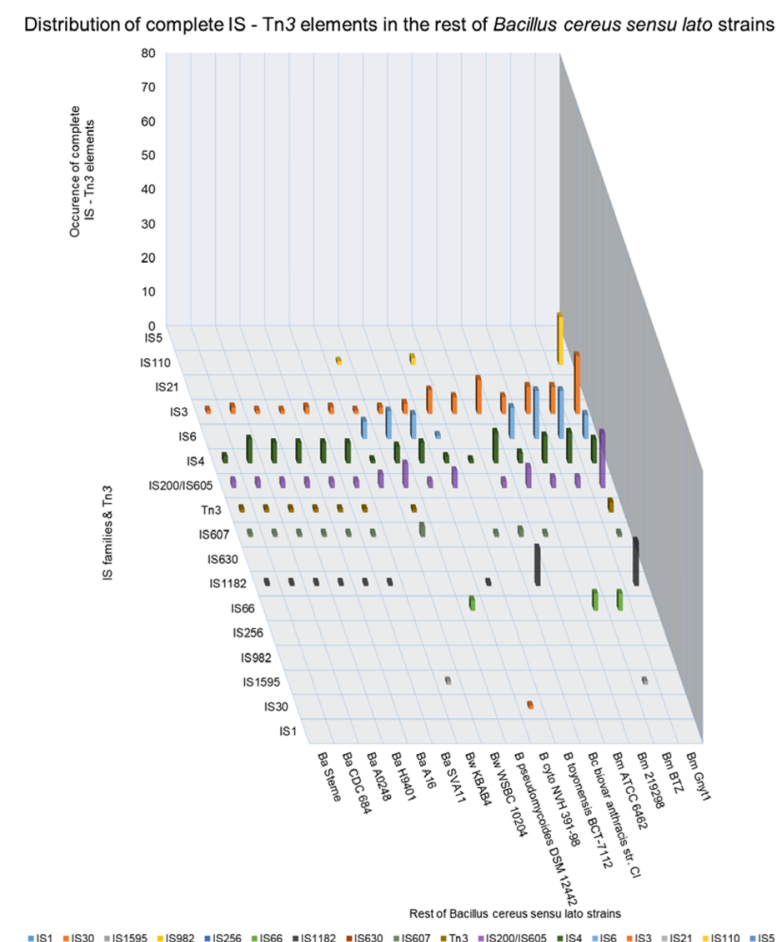

Fig. 1 Distribution of complete IS family members and Tn3 elements among the complete genomes of B. cereus s.I. The ISsaga web tool [51] was used for IS annotation. The number of complete ISs was detected in each strain's genome. Only families with at least one complete IS located on either the chromosome or plasmids are shown in this graphic representation. a IS distribution in 36 B. thuringiensis genomes, (b) 42 B. cereus S.S., (c) eight B. thuringiensis-like, and (d) six B. anthracis, four B. mycoides, two B. weihenstephanensis, one B. pseudomycoides, one B. cytotoxicus, one B. toyonensis and one $B$. cereus biovar anthracis

copies on either chromosomes or plasmids, whereas bcr18 is only found on plasmids. Concerning the other eleven repeats, only chromosomal copies were found (data not shown).

An interesting observation was an apparent negative correlation between the $b c r 1$ and $b c r 2$ elements. A statistical analysis was conducted to find the presence or absence of a negative or positive correlation between $B C R$ pairs for all the strains or by species. This analysis showed the existence of several significant correlations between pairs of $B C R$ elements $(p<0.05$; correlation coefficient is $\neq 0$ ) (Additional file 1: Table S3). These correlation pairs, either positive or negative, vary in number among species. Twenty correlation pairs were found in 


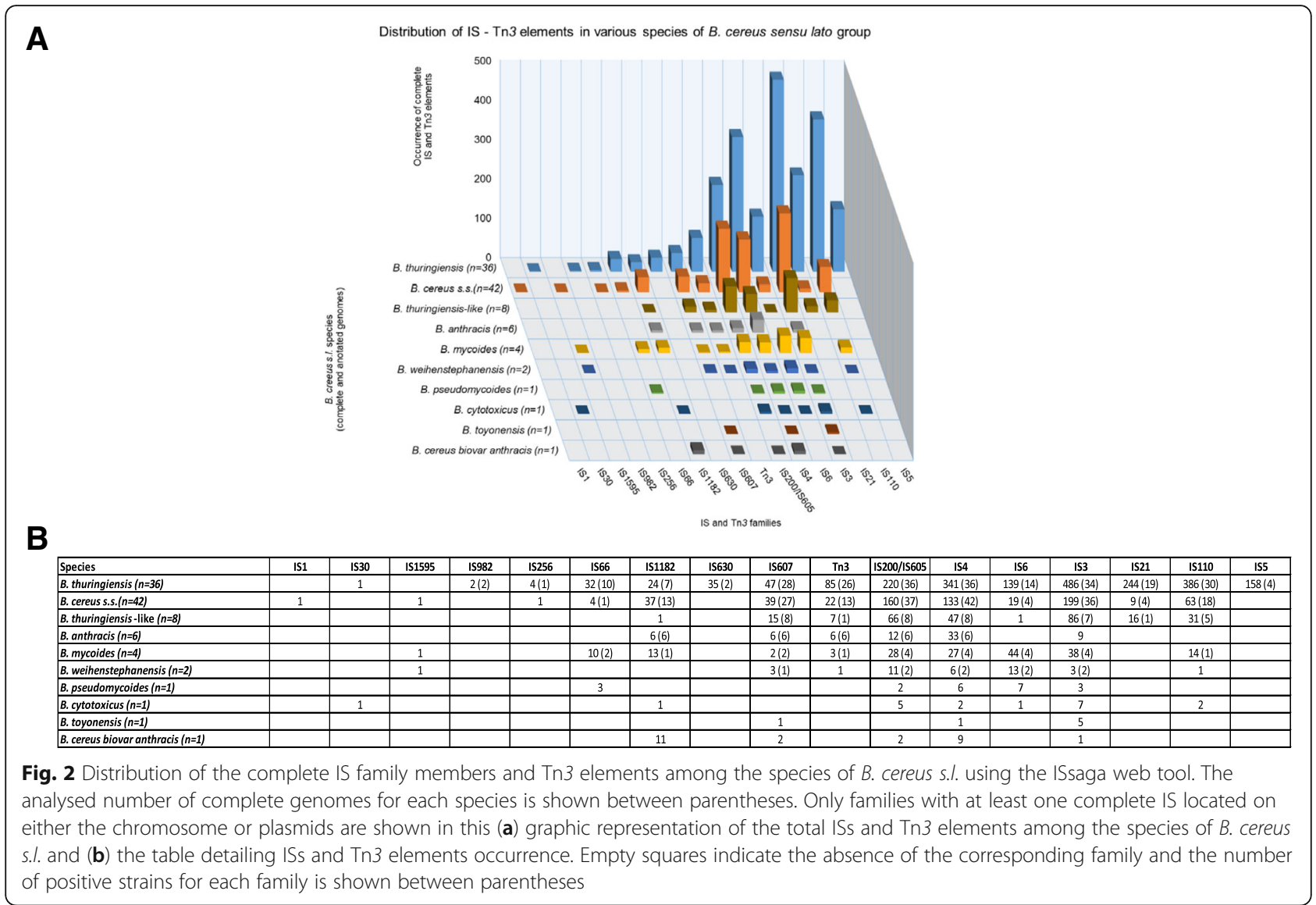

B. mycoides, 25 in B. cereus s.s., 14 in B. thuringiensis and 5 in $B$. thuringiensis-like (Additional file 1: Table S3-B). No significant correlation between $B C R$ elements was found in B. anthracis.

Several correlation pairs were also common between species. Therefore the coefficients of these common pairs were compared via a linear regression model at a 95\% confidence interval (Table 2) [52]. Between $B$. mycoides and $B$. thuringiensis and between $B$. mycoides and B. cereus s.s., the common correlation pairs were significantly different. On the contrary, the differences between the common correlation pairs of B. thuringiensis, B. thuringiensis-like and B. cereus s.s. were not significant.

\section{Group II introns}

The distribution of 30 known group II introns was analysed among the B. cereus s.l. genomes. The total number of group II introns varies from zero in B. toyonensis to 31 in strain HD29 of B. thuringiensis sv. galleriae. Although several group II introns were originally found in B. cereus s.s., they were also observed in B. thuringiensis and $B$. anthracis genomes (Additional file 1: Table S4). However, there is a remarkable difference in the average copy number of group II introns per strain between the different species. For instance, B. thuringiensis has an average of nine group II introns per strain, whereas $B$. cereus s.s. displays a much lower average of three elements per strain, with 59 and $44 \%$ of the elements located on plasmids, for B. thuringiensis and B. cereus s.s., respectively (Table 3 ). The presence of several copies of the same element (Additional file 1: Table S4) also suggests that it was once mobile. Another important observation is that most of group II introns located in $B$. cereus s.l. genomes belong to the RNA type IIB.

For B. thuringiensis, B. cereus s.s. and B. thuringiensis-like, group II introns are almost evenly distributed between chromosomes and plasmids, although with a slight bias (59\%) towards plasmids for B. thuringiensis (Table 3). Of note, $B$. anthracis has only chromosomal group II introns.

\section{A focus on $B$. thuringiensis toxin-carrying plasmids}

As mentioned above, virulence factors of the $B$. cereus group are often associated with TEs. In the case of $B$. thuringiensis, TEs found to be structurally associated with genes coding for delta-endotoxins include IS231 [38, 53], IS232 [54] and IS240 [55]. Therefore, the distribution of ISs and Tn3-like elements, BCRs and group II introns was analysed on $B$. thuringiensis toxin-carrying plasmids. Note that B. thuringiensis strains HD682, 


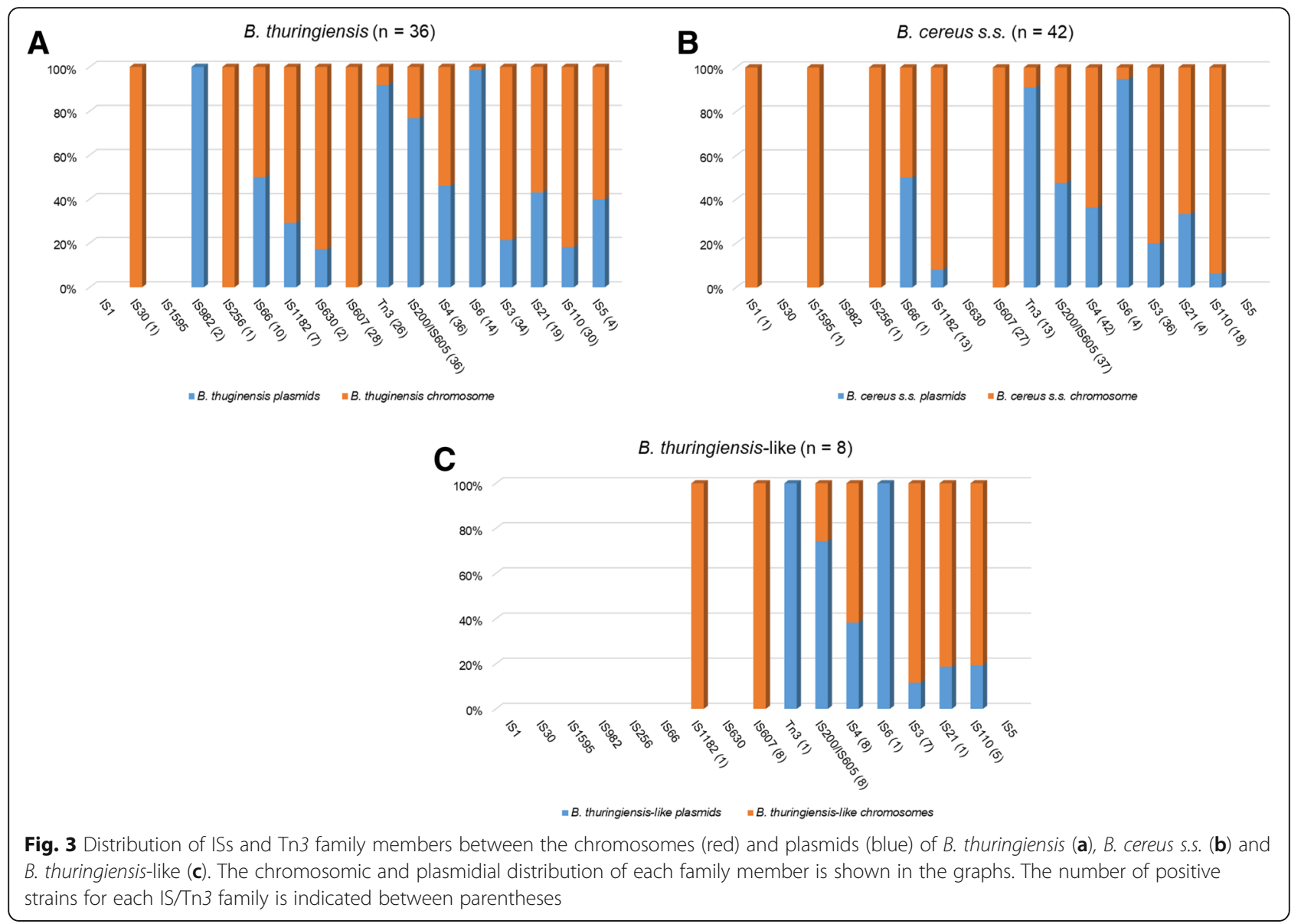

HD1011, c25 and YGD22-03 were not considered, since they carry only a fragment of the cry or cyt (delta-endotoxin and cytolysin, respectively) chromosomal genes.

Even though they represent only $30.6 \%$ of the total $B$. thuringiensis plasmid repertoire, toxin-carrying plasmids hold 36.9, 49.4 and $44.4 \%$ of the total plasmidial ISs, Tn3-like elements, $b c r 18$ repeats and group II introns, respectively. Also, ISs and Tn3-like elements represent in size $7.46 \%$ of the toxin-carrying plasmids vs. $5.33 \%$ for the other plasmids.

\section{Discussion}

B. cereus s.l. species are ecologically diverse but phylogenetically very close. Therefore, in this study, we aimed

Table 2 Correlation coefficient of BCRs pairs between species

\begin{tabular}{|c|c|c|c|}
\hline Compared species & Common correlating $B C R s$ pairs & $p$-value & Status \\
\hline \multirow[t]{2}{*}{ B. mycoides vs. B. cereus s.s. } & $b c r 1-b c r 2$ & 0.0008 & $\mathrm{~s}$ \\
\hline & bcr1 - bcr6 & 0.001 & s \\
\hline \multirow[t]{2}{*}{ B. mycoides vs. B. thuringiensis } & $b c r 1-b c r 2$ & 0.0035 & $s$ \\
\hline & $b c r 2-b c r 6$ & 0.013 & S \\
\hline \multirow[t]{5}{*}{ B. thuringiensis vs. B. cereus s.s. } & $b c r 1-b c r 2$ & 0.066 & NS \\
\hline & $b c r 1-b c r 5$ & 0.913 & NS \\
\hline & bcr6-bcr13 & 0.673 & NS \\
\hline & bcr9-bcr11 & 0.592 & NS \\
\hline & bcr11-bcr14 & 0.861 & NS \\
\hline B. thuringiensis-like vs. B. thuringiensis & $b c r 1-b c r 5$ & 0.169 & NS \\
\hline \multirow[t]{2}{*}{ B. thuringiensis-like vs. B. cereus s.s. } & $b c r 1-b c r 5$ & 0.149 & NS \\
\hline & bcr1-bcr11 & 0.106 & NS \\
\hline
\end{tabular}


Table 3 Distribution of group II introns in B. cereus s.l. genomes

\begin{tabular}{lll}
\hline Species & Average intron number/strain & Percentage of introns located on plasmids $(\%)$ \\
\hline B. thuringiensis $(n=36)$ & 9 & 59 \\
B. cereus sensu stricto $(n=42)$ & 3 & 44 \\
B. thuringiensis-like $(n=8)$ & 3.4 & 45 \\
B. anthracis $(n=6)$ & 3 & 0 \\
B. mycoides $(n=4)$ & 2 & 25 \\
B. weihenstephanensis $(n=2)$ & 0 & $\mathrm{NA}$ \\
B. pseudomycoides $(n=1)$ & 2 & 100 \\
B. cytotoxicus $(n=1)$ & 1 & 100 \\
B. toyonensis $(n=1)$ & 0 & $\mathrm{NA}$ \\
B. cereus biovar anthracis $(n=1)$ & 3 & 0
\end{tabular}

NA Not Applicable

to explore the variety and distribution of MGEs in 102 complete B. cereus s.l. strains and analyse their possible contribution in the clustering of the group species. Three MGEs types were taken into consideration: ISs and Tn3-like elements, Bacillus cereus repeats and group II introns.

First and foremost, the genomes of B. thuringiensis and B. cereus s.s. were checked for the presence or absence of cry, cyt and vip (vegetative insecticidal protein) toxin genes. Some studies have indeed highlighted the importance of toxin-carrying plasmids in the phenotypical heterogeneity of the $B$. cereus group [23], while others have claimed that toxin-coding genes are not proof enough of a strain's identity [21]. Based on several former phylogenetic studies, we chose to divide the analysed strains into B. thuringiensis (Cry+), B. cereus s.s. (Cry-) and B. thuringiensis-like (Additional file 1: Table S1).

Second, our data showed the distribution variability of ISs and Tn 3 elements among the different species, as well as among the different strains within the same species. For instance, $B$. thuringiensis presents an average of six plasmids per strain, with $6.18 \%$ of a plasmid being occupied by IS/Tn3 elements, vs. an average of two plasmids per strain and $3.73 \%$ of IS/Tn3 in B. cereus s.s. A strong positive correlation was found between TEs percentage per genome and the average number of plasmids per strain within a species, with a correlation coefficient of 0.91 . This correlation and the above numbers indicate that ISs and Tn3-like elements play an important role in plasmid plasticity. This is of chief importance in the case of $B$. thuringiensis whose particular life style relies on the presence, diversity and combination of entomotoxin genes. Through their transposition mechanism and their ability to mobilize neighbouring DNA fragments, TEs together with conjugative plasmids are likely to participate in the necessary shuffling of the virulent genetic determinants of $B$. thuringiensis. In fact, these TEs are known to be associated with virulence genes [38, 39, 54-56], thus being linked to the variety of plasmid types. In fact, these TEs may transpose via mechanisms that lead to a co-integrate structure formation between conjugative and non-mobilizable plasmids, thus affecting plasmid mobility.

Also, although some IS/Tn3 family patterns were noticeably different among the $B$. cereus s.l. species (e.g. IS110 family, see Fig. 1), their differential distribution could not be used as marker to discriminate the different species within the B. cereus group. This is due to the fact that these elements are not ubiquitously present in all the strains of a particular species, and therefore cannot be used to distinguish among the different species (Fig. 2).

As for $B C R s$, the specific repeat elements found in the B. cereus s.l. group, 18 distinct repeat types were analysed for their copy number and genomic distribution. Apart from bcr18, they are mostly located on chromosomes. Their copy number differs between strains and $B C R$ groups. These findings concur with those of previous studies regarding the general copy-number and distribution of the $B C R$ repeats [44]. A noteworthy observation is the presence of significant correlations between different $B C R$ pairs, which varied from one species to another. These correlations further confirm the tight phylogenetic association between $B$. thuringiensis and B. cereus s.S., and the clear distinction between these species and B. mycoides. Consequently, based on the correlation pair analysis, the copy numbers of the distinct repeat types, as well as the mostly chromosomic location of these elements, the 102 B. cereus s.l. strains, could be divided into three groups: group 1 (B. mycoides, $B$. weihenstephanensis and $B$. pseudomycoides), group 2 (B. thuringiensis, B. toyonensis, B. cereus s.s., B. cereus biovar anthracis and $B$. anthracis) and group 3 which contains the divergent B. cytotoxicus strain.

The catalytic RNA group II introns showed no differential distribution among the B. cereus s.l. species on the 
level of intron-species specificity, but are present in a higher copy number in the genomes of B. thuringiensis strains. Some group II introns are equally distributed between plasmids and chromosomes, and others are specific to either the chromosome or plasmids. Our analysis also indicated that some elements are inserted in non-coding regions (e.g. B.c.I1 and B.my.I1) while others are inserted into functional CDS (Coding DNA Sequence) (data not shown). Two examples are B.th.I1 and B.th.I2 located on the B. thuringiensis sv. kurstaki conjugative plasmid pAW63 (DQ025752.1), within a putative hydrolase and a VirD4-like component, respectively. B.th.I1 encodes an endonuclease, while B.th.I2 is an CDS-less intron [57].

A principal component analysis (PCA) using the copy numbers of the various TEs, following a Chord transformation of the data [58], was unable to establish the species delineation (data not shown). This indicates that a phylogenetic analysis based only on TEs distribution is not enough on its own, and should to be combined with other approaches for more significant results.

Toxin-carrying plasmids are one of many plasmid types found in $B$. thuringiensis strains. These virulent plasmids are not only vital for B. thuringiensis insecticidal activity, but they are also important for other cellular functions such as sporulation, germination or horizontal gene transfer [5]. This is particularly true for the $B$. thuringiensis toxin-carrying plasmids that represent $30.6 \%$ of the plasmid pool. Interestingly, these plasmids carry a large portion of the total plasmidial IS-Tn3-like elements, BCRs and group II introns, with $7.46 \%$ (in size) of the toxin-carrying plasmids being ISs and Tn3-like elements vs. 5.33\% for the other plasmids. As indicated above, this observation strongly suggests that these TEs elements have somehow contributed to the diversity of $B$. thuringiensis virulence, and hence its adaptation to the insect host spectrum. This is in line with previous observations linking ISs and Tn3-like elements to cry and cyt toxin genes and the presumed contribution of the formers in the mobility of the latters $[38,56,59]$.

The variety and distribution of these mobile elements in other bacterial species is noteworthy. Concerning ISs and Tn3-like elements, the families described here can be found in several other species. An example is the well-known IS4 family [60]. Members of this family are abundant in the B. cereus s.l. group (Fig. 2). In total, the latest data in the ISFinder database states that this family is found in 204 Gram-positive and Gram-negative bacterial species as well as in archaea. As indicated above, the $B C R$ repeats are specific to the $B$. cereus group, and have not been found in any other species including those belonging to the Bacillus genera.

\section{Conclusion}

This study underlines the great diversity of ISs and Tn3-like elements, BCRs and group II introns among strains and species of the B. cereus s.l. group. We took special care in analysing "clean" bacterial species, as in Cry+ B. thuringiensis and Cry- B. cereus s.s., not relying solely on the database division. This study is therefore the first to analyse the distribution of more than one TE type in 102 complete B. cereus s.l. genomes. Analysis of these TEs is in agreement with previous phylogenetic studies that were unable to draw a clear line between $B$. cereus s.s. and $B$. thuringiensis. Finally, although mobile elements are not reliable on their own for establishing clear-cut phylogenetic clades, some of them, especially $B C R$ elements, may serve as additional markers used alongside whole genome-based approaches.

\section{Methods \\ Genomes}

The genomes of B. cereus s.l. analysed in this study are completely sequenced, assembled and annotated and were downloaded from the NCBI genome database [68]. Since repeated elements may impair the complete assembly of a genome and are often located on the extremities of a contig or a scaffold, draft genomes with a contig or scaffold level assembly were not considered. In total, $42 B$. thuringiensis, 44 B. cereus s.s., 6 B. anthracis, 4 B. mycoides, 2 B. weihenstephanensis genomes and one genome of $B$. cytotoxicus, $B$. pseudomycoides, B. toyonensis and B. cereus biovar anthracis were analysed for their content in IS elements, class II transposable elements belonging to the $\mathrm{Tn} 3$ family, consensus $B C R$ sequences and group II introns (Table 1 and Additional file 1: Table S1). Since B. anthracis strains are highly clonal, only six were chosen randomly from the fifty complete genomes available in the NCBI genome database. Given the close phylogenetic relationship between $B$. thuringiensis and B. cereus s.s., all their genomes were also inspected for the presence of delta-endotoxin coding genes. This was done by MegaBLAST search of toxins from 74 cry, three cyt and three vip gene families from the ad hoc database [61], further dividing the genome ensemble for each species into cry+ or cry- strains (e.g. B. thuringiensis vs. B. thuringiensis cry- and B. cereus vs. B. cereus cry+). Therefore B. thuringiensis cry- and B. cereus cry+ strains were grouped and assigned as $B$. thuringiensis-like.

\section{Detection of ISs and Tn3-like elements}

Despite their small size and simple organization, ISs are rarely annotated correctly in sequenced genomes. A correct ISs identification requires both DNA and protein levels. Therefore, the ISFinder team has developed ISsaga (Insertion Sequence semi-automatic genome annotation) [51]. This online tool allows the annotation of complete or partial ISs as well as Tn3 family elements. It 
first identifies the IS-associated CDSs and then runs a BLASTX analysis to confirm all the potential transposases. This analysis is followed by a cross-reference of the obtained nucleotide sequences with the ISFinder database [62].

For this study, ISsaga was used to annotate the complete genomes (chromosomes and plasmids) in "Fasta" format and subsequently to conduct a manual verification of the results. This allowed us to extract the copy number of complete ISs and Tn3 elements and to calculate their percentage in each genome.

\section{Detection of BCRs and group II intron elements}

Analysis of the "Bacillus cereus repeats" $(B C R)$ was done using nucleotide BLAST searches of the consensus bcr 1bcr18 [44] sequences against complete B. cereus s.l. genomes. Based on former studies [44,63], and based on our observations, the algorithm parameters for MegaBLAST $[64,65]$ were set as follow: the word size - length of a seed that allows the BLAST engine to initiate an alignment - was set at 16; the opening and extension of a gap were both set at 2; expect range was set between 0 and 0.1 . Hits that covered at least $50 \%$ of the sequence length, and had a minimum of $75 \%$ identity were considered as repeats. Correlation between the various $B C R s$ repeats was calculated using JMP ${ }^{\circ}$ (JMP $^{\circ}$, version Pro 13. SAS institute Inc., NC. 1989-2007). The significance of the correlation between BCRs pairs for each species was then evaluated at a $95 \%$ confidence level. Species with only one or two complete genomes were excluded from this statistical analysis.

The same nucleotide MegaBLAST parameters were used to retrieve known group II introns from the bacterial group II intron database (http://webapps2.ucalgary. ca/ groupii/, [66] [67] in addition to B.th.I3i [48] which was absent from the mentioned database. This includes 27 elements with CDSs coding the IEP and three CDS-less elements.

\section{Additional file}

Additional file 1: Table S1A. Accession numbers of the analyzed $B$. cereus s.l. replicons. B. thuringiensis cry- and B. cereus s.s. cry+ are placed under $B$. thuringiensis-like. Table S1B. Genomic details of eight $B$. thuringiensis $c r y$ - and four B. cereus s.s. $\mathrm{cry}+$ Table S2. Heat map of the total bcr number in the complete genomes of nine B. cereus s.l. species. The heat map is arranged by species and decreasing bcrl occurrence. Table S3A. Correlation pairs for the 102 analyzed B. cereus s.l. genomes. Table S3B. Correlation pairs for the 102 analyzed B. cereus s.l. genomes by species. Table S4A. Heat map and distribution of group II intron types in the complete genomes of 9 B. cereus sensu lato species. Table S4B. Heat map and distribution of group II introns in the complete genomes of 9 B. cereus sensu lato species. (DOCX $1276 \mathrm{~kb}$ )

\section{Abbreviations}

B.: Bacillus; BCR(s): Bacillus cereus repeat(s); CDS(s): Coding DNA Sequence(s); cry: crystal or delta-endotoxin gene; cyt: cytotoxin gene;
GTEvaluator: Genome Target Evaluator; ICE(s): Integrative and Conjugative Element(s); IEP(s): Intron Encoded Protein(s); IR(s): Inverted Repeat(s); IS(s): Insertion Sequence(s); ISsaga: Insertion Sequence semi-automatic genome annotation; MGE(s): Mobile Genetic Element(s); MIC(s): Mobile Insertion Cassette(s); MITE(s): Miniature Inverted repeat Transposable Element(s); MLST: Multi Locus Sequence Typing; NCBI: National Center for Biotechnology Information; PCA: Principal Component Analysis; s.l: sensu lato; s.s.: sensu stricto; sv:: serovar; $T E(s)$ : Transposable Element(s); $T n(s)$ : class II transposons; vip: vegetative insecticidal protein gene; vs.: versus

\section{Acknowledgements}

We are indebted to the members of the ISFinder team (https://www-is biotoul.fr), in particular P. Siguier and M. Chandler, for their precious help in mining the IS elements.

\section{Funding}

This study was financially supported by the National Fund for Scientific Research (FNRS, Belgium) through grants to J. Mahillon, the Université catholique de Louvain (UCLouvain) through a grant to N. Fayad, the National Council for Scientific Research in Lebanon (CNRS-L) through grants to N. Fayad and M. Kallassy Awad and the PCSI of the AUF-BMO for researcher mobility. These funding bodies did not directly participate to the design, interpretation and writing of this study.

\section{Availability of data and materials}

The datasets used and/or analyzed during the current study are available from the corresponding author on reasonable request. Additional data are available at BMC Genomics online.

\section{Authors' contributions}

NF performed all the bioinformatic analyses. NF, MKA and JM contributed in writing the manuscript with NF and JM being the major contributors. NF, MKA and JM approved the final manuscript. All authors read and approved the final manuscript.

\section{Consent for publication}

Not applicable.

\section{Competing interests}

The authors declare that they have no competing interests.

\section{Publisher's Note}

Springer Nature remains neutral with regard to jurisdictional claims in published maps and institutional affiliations.

\section{Author details}

${ }^{1}$ Laboratory of Food and Environmental Microbiology, Earth and Life Institute, UCLouvain, Croix du Sud, 2 - L7.05.12, B-1348 Louvain-la-Neuve, Belgium. ${ }^{2}$ Laboratory of Biodiversity and Functional Genomics, Faculty of Science, Université Saint-Joseph de Beyrouth, Beirut, Lebanon.

Received: 31 December 2018 Accepted: 3 May 2019 Published online: 29 May 2019

\section{References}

1. Jensen $\mathrm{GB}$, Hansen BM, Eilenberg J, Mahillon J. The hidden lifestyles of Bacillus cereus and relatives. Environ Microbiol. 2003;5:631-40.

2. Okinaka RT, Cloud K, Hampton O, Hoffmaster AR, Hill KK, Keim P, et al. Sequence and organization of pXO1, the large Bacillus anthracis plasmid harboring the anthrax toxin genes. J Bacteriol. 1999;181:6509-15.

3. Bhatnagar R, Batra S. Anthrax toxin. Crit Rev Microbiol. 2001;27:167-200.

4. Palma L, Muñoz D, Berry C, Murillo J, Caballero P. Bacillus thuringiensis toxins: an overview of their biocidal activity. Toxins (Basel). 2014;6:3296-325. https://doi.org/10.3390/toxins6123296.

5. Gillis A, Fayad N, Makart L, Bolotin A, Sorokin A, Kallassy M, et al. Role of plasmid plasticity and mobile genetic elements in the entomopathogen Bacillus thuringiensis serovar israelensis. FEMS Microbiol Rev. 2018:1-28. https://doi.org/10.1093/femsre/fuy034

6. Lechner S, Mayr R, Francis KP, Prüss BM, Kaplan T, Wiessner-Gunkel E, et al. Bacillus weihenstephanensis sp. nov. is a new psychrotolerant species of the 
Bacillus cereus group. Int J Syst Bacteriol. 1998;48(Pt 4):1373-82. https://doi. org/10.1099/00207713-48-4-1373.

7. Guinebretière M-H, Auger S, Galleron N, Contzen M, De Sarrau B, De Buyser $M-L$, et al. Bacillus cytotoxicus sp. nov. is a novel thermotolerant species of the Bacillus cereus group occasionally associated with food poisoning. Int $J$ Syst Evol Microbiol. 2013;63:31-40. https://doi.org/10.1099/ijs.0.030627-0.

8. Nakamura LK. Bacillus pseudomycoides sp. nov. Int I Syst Bacteriol. 1998;48: 1031-5. https://doi.org/10.1099/00207713-48-3-1031.

9. Jiménez G, Urdiain M, Cifuentes A, López-López A, Blanch AR, Tamames J, et al. Description of Bacillus toyonensis sp. nov., a novel species of the Bacillus cereus group, and pairwise genome comparisons of the species of the group by means of ANI calculations. Syst Appl Microbiol. 2013;36:38391. https://doi.org/10.1016/j.syapm.2013.04.008.

10. Brézillon C, Haustant M, Dupke S, Corre J-P, Lander A, Franz T, et al. Capsules, toxins and AtxA as virulence factors of emerging Bacillus cereus biovar anthracis. PLoS Negl Trop Dis. 2015;9:e0003455. https://doi.org/10. 1371/journal.pntd.0003455.

11. Jung MY, Jung M-Y, Paek WK, Park I-S, Han J-R, Sin Y, et al. Bacillus gaemokensis sp. nov., isolated from foreshore tidal flat sediment from the Yellow Sea. J Microbiol. 2010;48:867-71. https://doi.org/10.1007/s12275-0100148-0.

12. Jung MY, Kim J-S, Paek WK, Lim J, Lee H, II KP, et al. Bacillus manliponensis sp. nov., a new member of the Bacillus cereus group isolated from foreshore tidal flat sediment. J Microbiol. 2011;49:1027-32. https://doi.org/10.1007/ s12275-011-1049-6.

13. Liu B, Liu G-H, Hu G-P, Sengonca C, Cetin S, Lin N-Q, et al. Bacillus bingmayongensis sp. nov., isolated from the pit soil of emperor Qin's Terracotta warriors in China. Antonie Van Leeuwenhoek. 2014;105:501-10. https://doi.org/10.1007/s10482-013-0102-3.

14. Miller RA, Beno SM, Kent DJ, Carroll LM, Martin NH, Boor KJ, et al. Bacillus wiedmannii sp. nov., a psychrotolerant and cytotoxic Bacillus cereus group species isolated from dairy foods and dairy environments. Int J Syst Evol Microbiol. 2016;66:4744-53. https://doi.org/10.1099/ijsem.0.001421.

15. Kamar R, Gohar M, Jéhanno I, Réjasse A, Kallassy M, Lereclus D, et al. Pathogenic potential of Bacillus cereus strains as revealed by phenotypic analysis. J Clin Microbiol. 2013;51:320-3.

16. Maughan $\mathrm{H}$, Van der Auwera G. Bacillus taxonomy in the genomic era finds phenotypes to be essential though often misleading. Infect Genet Evol. 2011;11:789-97. https://doi.org/10.1016/j.meegid.2011.02.001.

17. Bazinet AL. Pan-genome and phylogeny of Bacillus cereus sensu lato. BMC Evol Biol. 2017;17:1-16.

18. Didelot $X$, Barker M, Falush D, Priest FG. Evolution of pathogenicity in the Bacillus cereus group. Syst Appl Microbiol. 2009;32:81-90.

19. Blanco-Míguez A, Meier-Kolthoff JP, Gutiérrez-Jácome A, Göker M, FdezRiverola F, Sánchez B, et al. Improving phylogeny reconstruction at the strain level using peptidome datasets. PLoS Comput Biol. 2016;12:1-19.

20. Zheng J, Gao Q, Liu L, Liu H, Wang Y, Peng D, et al. Comparative genomics of Bacillus thuringiensis reveals a path to specialized exploitation of multiple invertebrate hosts. MBio. 2017:8:1-14.

21. Liu Y, Lai Q, Göker M, Meier-Kolthoff JP, Wang M, Sun Y, et al. Genomic insights into the taxonomic status of the Bacillus cereus group. Sci Rep. 2015;5:1-11. https://doi.org/10.1038/srep14082.

22. Felten A, Guillier L, Radomski N, Mistou MY, Lailler R, Cadel-Six S. Genome target evaluator (GTEvaluator): a workflow exploiting genome dataset to measure the sensitivity and specificity of genetic markers. PLoS One. 2017; 12:1-12.

23. Patino-Navarrete R, Sanchis V. Evolutionary processes and environmental factors underlying the genetic diversity and lifestyles of Bacillus cereus group bacteria. Res Microbiol. 2017;168:309-18.

24. Berry C, O'Neil S, Ben-dov E, Jones AF, Murphy L, Quail MA, et al. Complete sequence and organization of pBtoxis, the toxin-coding plasmid of Bacillus thuringiensis subsp. israelensis. Appl Environ Microbiol. 2002;68:5082-95.

25. Stein C, Jones GW, Chalmers T, Berry C. Transcriptional analysis of the toxincoding plasmid pBtoxis from Bacillus thuringiensis subsp. israelensis. Appl Environ Microbiol. 2006;72:1771-6.

26. Makart $\mathrm{L}$, Gillis $\mathrm{A}$, Mahillon J. pXO16 from Bacillus thuringiensis serovar israelensis: almost $350 \mathrm{~kb}$ of terra incognita. Plasmid. 2015;80:8-15. https:// doi.org/10.1016/.jplasmid.2015.03.002.

27. Modrie P, Beuls E, Mahillon J. Differential transfer dynamics of pAW63 plasmid among members of the Bacillus cereus group in food microcosms. J Appl Microbiol. 2010;108:888-97.
28. Gillis A, Guo S, Bolotin A, Makart L, Sorokin A, Mahillon J. Detection of the cryptic prophage-like molecule pBtic235 in Bacillus thuringiensis subsp. israelensis. Res Microbiol. 2017;168:319-30. https://doi.org/10.1016/j.resmic. 2016.10.004.

29. Van der Auwera GA, Andrup L, Mahillon J. Conjugative plasmid pAW63 brings new insights into the genesis of the Bacillus anthracis virulence plasmid pXO2 and of the Bacillus thuringiensis plasmid pBT9727. BMC Genomics. 2005;6:103. https://doi.org/10.1186/1471-2164-6-103.

30. Makart L, Gillis A, Hinnekens P, Mahillon J. A novel T4SS-mediated DNA transfer used by pXO16, a conjugative plasmid from Bacillus thuringiensis serovar israelensis. Environ Microbiol. 2018;20:1550-61. https://doi.org/10. 1111/1462-2920.14084.

31. Johnson CM, Grossman AD. Integrative and conjugative elements (ICEs): what they do and how they work. Annu Rev Genet. 2015;49:557-601.

32. Craig NL, Gragie R, Gellert M, Lambowitz A. Mobile DNA II. Washington DC: ASM Press; 2002.

33. Siguier $\mathrm{P}$, Gourbeyre E, Varani A, Ton-hoang BAO, Chandler M. Everyman's guide to bacterial insertion sequences. Microbiol Spectr. 2015;3:1-35.

34. Nicolas E, Lambin M, Dandoy D, Galloy C, Nguyen N, Oger CA, et al. The Tn3-family of replicative transposons. Microbiol Spectr. 2015;1:1-32.

35. Chen Y, Braathen P, Léonard C, Mahillon J. MIC231, a naturally occurring mobile insertion cassette from Bacillus cereus. Mol Microbiol. 1999;32:657-68.

36. Mazel D. Integrons: agents of bacterial evolution. Nat Rev Microbiol. 2006;4: 608-20. https://doi.org/10.1038/nrmicro1462.

37. Økstad OA, Tourasse NJ, Stabell FB, Sundfær CK, Egge-Jacobsen W, Risøen PA, et al. The bcrl DNA repeat element is specific to the Bacillus cereus group and exhibits mobile element characteristics. J Bacteriol. 2004;186:7714-25.

38. Mahillon J, Seurinck J, van Rompuy L, Delcour J, Zabeau M. Nucleotide sequence and structural organization of an insertion sequence element (IS231) from Bacillus thuringiensis strain berliner 1715. EMBO J. 1985;4:3895-9.

39. Mahillon J, Lereclus D. Structural and functional analysis of Tn4430: identification of an integrase-like protein involved in the co-integrateresolution process. EMBO J. 1988;7:1515-26.

40. Mei X, Xu K, Yang L, Yuan Z, Mahillon J, Hu X. The genetic diversity of cereulide biosynthesis gene cluster indicates a composite transposon Tnces in emetic Bacillus weihenstephanensis. BMC Microbiol. 2014;14:149. https:// doi.org/10.1186/1471-2180-14-149.

41. He S, Corneloup A, Guynet C, Lavatine L, Caumont-Sarcos A, Siquier P, et al. The IS200/IS605 family and "Peel and paste" single-strand transposition mechanism. Microbiol Spectr. 2015;3:1-21. https://doi.org/10.1128/ microbiolspec.MDNA3-0039-2014.

42. Mahillon J. Insertion sequence elements and transposons in Bacillus. In: Applications and systematics of Bacillus and relatives. Oxford, UK: Blackwell Science Ltd; 2002. p. 236-253. doi:https://doi.org/10.1002/9780470696743. ch16.

43. Siguier $P$, Gourbeyre E, Chandler M. Bacterial insertion sequences: their genomic impact and diversity. FEMS Microbiol Rev. 2014;38:865-91.

44. Kristoffersen SM, Tourasse NJ, Kolstø AB, Økstad OA. Interspersed DNA repeats bcr1-bcr18 of Bacillus cereus group bacteria form three distinct groups with different evolutionary and functional patterns. Mol Biol Evol. 2011;28:963-83.

45. Robart AR, Zimmerly S. Group II intron retroelements: function and diversity. Cytogenet Genome Res. 2005;110:589-97.

46. Zimmerly S, Semper C. Evolution of group II introns. Mob DNA. 2015;6:1-19. https://doi.org/10.1186/s13100-015-0037-5.

47. Lehmann K, Schmidt U. Group II introns: structure and catalytic versatility of large natural ribozymes. Crit Rev Biochem Mol Biol. 2003;38:249-303. https:// doi.org/10.1080/713609236.

48. Tourasse NJ, Kolstø AB. Survey of group I and group II introns in 29 sequenced genomes of the Bacillus cereus group: insights into their spread and evolution. Nucleic Acids Res. 2008;36:4529-48.

49. Sheppard AE, Poehlein A, Rosenstiel P, Liesegang H, Schulenburg H. Complete genome sequence of Bacillus thuringiensis strain $407 \mathrm{cry}$. Genome Announc. 2013;1:e00158-12. https://doi.org/10.1128/genomeA.00158-12.

50. He J, Shao X, Zheng H, Li M, Wang J, Zhang Q, et al. Complete genome sequence of Bacillus thuringiensis mutant strain BMB171. J Bacteriol. 2010; 192:4074-5. https://doi.org/10.1128/JB.00562-10.

51. Varani AM, Siguier P, Gourbeyre E, Charneau V, Chandler M. ISsaga is an ensemble of web-based methods for high throughput identification and semi-automatic annotation of insertion sequences in prokaryotic genomes. Genome Biol. 2011;12:R30. https://doi.org/10.1186/gb-2011-12-3-r30. 
52. Cohen J, Cohen P, West SG, Aiken LS. Applied multiple regression/ correlation analysis for the behavioral sciences, 3rd ed. Mahwah: Lawrence Erlbaum Associates Publishers; 2003.

53. Mahillon J, Rezsöhazy R, Hallet B, Delcour J. IS231 and other Bacillus thuringiensis transposable elements: a review. Genetica. 1994;93:13-26.

54. Menou G, Mahillon J, Lecadet MM, Lereclus D. Structural and genetic organization of IS232, a new insertion sequence of Bacillus thuringiensis. J Bacteriol. 1990;172:6689-96.

55. Delécluse A, Bourgouin C, Klier A, Rapoport G. Nucleotide sequence and characterization of a new insertion element, IS240, from Bacillus thuringiensis israelensis. Plasmid. 1989:71-8.

56. Fiedoruk K, Daniluk T, Mahillon J, Leszczynska K, Swiecicka I. Genetic environment of cry 1 genes indicates their common origin. Genome Biol Evol. 2017;9:2265-75

57. Van der Auwera G, Mahillon J. Transcriptional analysis of the conjugative plasmid pAW63 from Bacillus thuringiensis. Plasmid. 2008;60:190-199. doi: https://doi.org/10.1016/j.plasmid.2008.07.003.

58. Legendre P, Gallagher ED. Ecologically meaningful transformations for ordination of species data. Oecologia. 2001;129:271-80.

59. Mahillon J, Seurinck J, Delcour J, Zabeau M. Cloning and nucleotide sequence of different iso-IS231 elements and their structural association with the Tn4430 transposon in Bacillus thuringiensis. Gene. 1987:51:187-96. https://doi.org/10.1016/0378-1119(87)90307-6.

60. De Palmenaer D, Siguier P, Mahillon J. IS4 family goes genomic. BMC Evol Biol. 2008:8:18

61. Bacillus thuringiensis toxin nomenclature database. http://www. btnomenclature.info/. Accessed Feb 2018.

62. ISFinder. https://isfinder.biotoul.fr/.

63. Tourasse NJ, Helgason E, Økstad OA, Hegna IK, Kolstø AB. The Bacillus cereus group: novel aspects of population structure and genome dynamics. J Appl Microbiol. 2006;101:579-93.

64. Zhang Z, Schwartz S, Wagner L, Miller W. A greedy algorithm for aligning DNA sequences. J Comput Biol. 2000;7:203-14. https://doi.org/10.1089/ 10665270050081478

65. Morgulis A, Coulouris G, Raytselis Y, Madden TL, Agarwala R, Schäffer AA. Database indexing for production MegaBLAST searches. Bioinformatics. 2008:24:1757-64. https://doi.org/10.1093/bioinformatics/btn322.

66. Candales MA, Duong A, Hood KS, Li T, Neufeld RAE, Sun R, et al. Database for bacterial group II introns. Nucleic Acids Res. 2012;40:187-90. https://doi. org/10.1093/nar/gkr1043.

67. Bacterial group II introns database. http://webapps2.ucalgary.ca/ groupii/. Accessed Apr 2018.

68. NBCl genome database. https://www.ncbi.nlm.nih.gov/genome. Last accessed February 2018

Ready to submit your research? Choose BMC and benefit from:

- fast, convenient online submission

- thorough peer review by experienced researchers in your field

- rapid publication on acceptance

- support for research data, including large and complex data types

- gold Open Access which fosters wider collaboration and increased citations

- maximum visibility for your research: over $100 \mathrm{M}$ website views per year

At $\mathrm{BMC}$, research is always in progress.

Learn more biomedcentral.com/submissions 